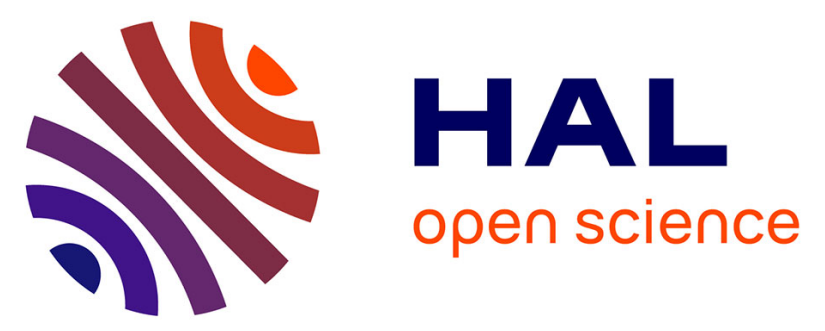

\title{
State of the art of electromagnetic energy for welding and powder compaction
}

Prabu Manoharan, Arun Prasath Manogaran, Didier Priem, Surendar Marya, Guillaume Racineux

\section{To cite this version:}

Prabu Manoharan, Arun Prasath Manogaran, Didier Priem, Surendar Marya, Guillaume Racineux. State of the art of electromagnetic energy for welding and powder compaction. Welding in the World, 2013, 57 (6), pp.867-878. 10.1007/s40194-013-0080-0 . hal-03284762

\section{HAL Id: hal-03284762}

\section{https://hal.science/hal-03284762}

Submitted on 14 Jul 2021

HAL is a multi-disciplinary open access archive for the deposit and dissemination of scientific research documents, whether they are published or not. The documents may come from teaching and research institutions in France or abroad, or from public or private research centers.
L'archive ouverte pluridisciplinaire $\mathbf{H A L}$, est destinée au dépôt et à la diffusion de documents scientifiques de niveau recherche, publiés ou non, émanant des établissements d'enseignement et de recherche français ou étrangers, des laboratoires publics ou privés. 


\title{
State of the art of electromagnetic energy for welding and powder compaction
}

\author{
Prabu Manoharan • Arun Prasath Manogaran • \\ Didier Priem • Surendar Marya • Guillaume Racineux
}

\begin{abstract}
The innovation of advanced materials and their application to engineering structures can be related to their ease of fabricating defect-free parts. The identification of various energy sources has resulted in various new processing techniques in manufacturing and electromagnetic energy is one which offers promising qualities for high-velocity forming, welding, and compaction of metals. Bimetallic joint designs were proposed in automobiles to reduce the weight and to take advantage of properties of different metals in the same construction. Joining by fusion is impossible in certain cases due to huge differences in melting point, thermal conductivity, volumetric specific heat, and coefficient of thermal expansion. In the present study, magnetic-pulse welding of a $\mathrm{Cu} / \mathrm{Al}$ joint and an ODS alloy is investigated. The formation of intermetallic phases and interface morphology is presented along with a quantitative analysis for temperature in the $\mathrm{Al} / \mathrm{Cu}$ joint. Also, initial investigations on the application of electromagnetic energy for compaction of aluminum powders are reported.
\end{abstract}

Keywords Pulse welding · Phase Diagrams · Magneticpulse welding $\cdot$ Oxides $\cdot$ Materials

\section{Introduction}

Automobile, aerospace, and nuclear industries have been the driving factors for the search of light-weight and high-

P. Manoharan $(\triangle) \cdot$ A. P. Manogaran $\cdot$ D. Priem $\cdot$ S. Marya $\cdot$

G. Racineux

Institute de recherche en génie civil et génie mécanique, UMR

CNRS 6183 Ecole Centrale Nantes, 1 Rue de la Noë, Nantes 44321

Cedex 3, France

e-mail: prabu.manoharan@ec-nantes.fr strength alloys and their associated process. Bimetallic joint designs were proposed in automobiles to reduce the weight and to take advantage of properties of different metals in the same location. Joining by fusion is impossible in certain cases due to huge differences in melting point, thermal conductivity, volumetric specific heat, and coefficient of thermal expansion. From the phase diagram, equilibrium between aluminum and copper, as shown in Fig. 1, clearly indicates the possible formation of several intermetallic phases during fusion. Thus, the bimetallic joints should be made without base-metal melting. In explosive welding, chemical energy is used to generate impact between parts and resulting interfacial joints has been extensively studied and exploited in industrial cases for welding thick sections [2]. Today, the use of electromagnetic energy has been successfully demonstrated for forming, joining, welding, and compaction of metal powders and it offers numerous advantages in an industrial environment such as,

- Superior quality of products when compared to its competing processes

- Can be easily automated

- High-volume production due to short process time

- Good control over process parameters

- Demands less operator skill.

However, the use of electromagnetic energy in industries is limited due to lack of knowledge about the physics of the process. In the present study, the application of electromagnetic energy for welding and compaction of metal powders is investigated. Magnetic-pulse welding (MPW), also known as electromagnetic welding, is studied for a bimetallic joint combination $\mathrm{Al} / \mathrm{Cu}$ and for welding a ferritic oxide dispersionstrengthened (ODS) alloy. Electromagnetic welding looks promising for welding bimetals and some advanced materials which are impossible to weld using conventional processes. 


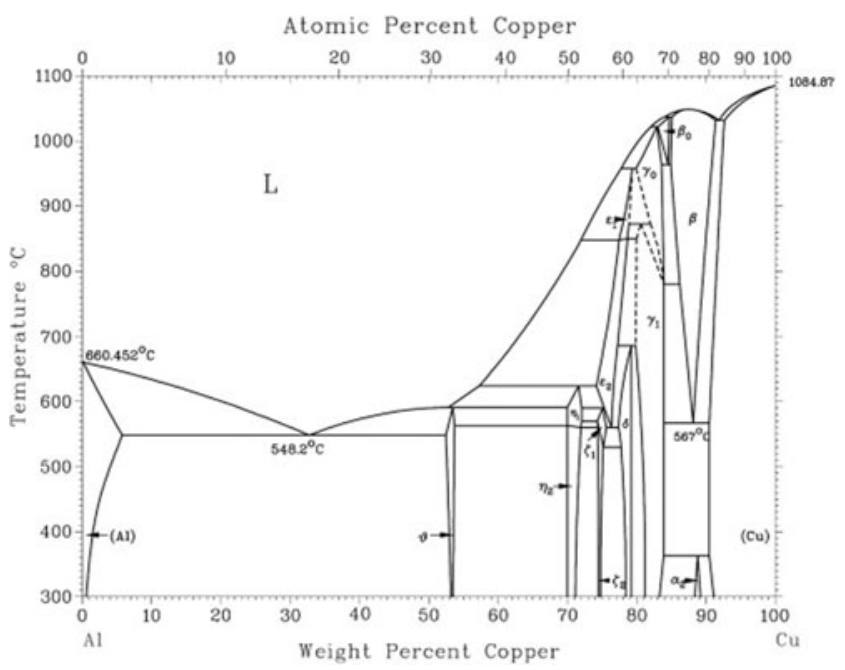

Fig. 1 Aluminum-copper phase diagram [1]

The electromagnetic compaction process is a cold compaction process and an ideal candidate to compact powders where increase in temperature could cause detrimental effects. An electromagnetic compaction system realized through several developmental steps is reported in the present study and compacts of very good density have been produced using aluminum powders.

\section{Magnetic-pulse welding}

Magnetic-pulse welding is a process of the joining of two parts using electromagnetic energy. The parts to be welded are accelerated and collide with each other with very high velocity. This dynamic impact causes severe plastic deformation on the surface and metallurgical bonding takes place. Even though the process has been known for over 40 years, the industrialization of the process took place only at the end of the twentieth century $[3,4]$. Similar to explosive welding, a wavy appearance of the interface is observed in MPW joints and the amplitude of the wave varies along the length of the joints [5]. There exists contradicting views explaining the mechanism of bond formation in MPW. During initial stages, the process is considered cold and an increase in hardness at the interface is related to the extreme plastic strain due to impact [6]. However, recently, the possibility of fusion at the interface is reported by many researchers. Given the rapid nature of the process and extreme pressure involved, it is very difficult to measure the temperature.

Stern and Aizenshtein investigated the interface layer formed in MPW to analyze the bond-formation mechanism and they observed an increase in hardness in the interface and concluded that it is due to the formation of metastable intermetallic compounds due to melting and rapid cooling [7]. Marya et al. characterized the electromagnetic welds between dissimilar welds and they classified the different zones of mechanical inter locking in the welded region. Good welding takes places in the zone where optimum energy and impact velocity is imposed on the specimen. From analysis of intermetallic phases, the possibility of the interface temperature reaching the point of fusion is high. Thus the properties of the weld are determined by intermetallic phases in the welded region. They have also observed spherical shrinkage voids in the case of aluminum-copper welded samples [8]. Thus, it is essential to analyze the influence of energy and impact velocity on the temperature during the process. The extension of MPW to flat plates is carried out by modifying the solenoid coil into 1-turn flat coil $[9,10]$. Zhang et al. numerically modeled the MPW process based on the coupled thermal and electromagnetic model using the electromagnetism module in LS-DYNA. The model is used to calculate the velocity and temperature field during the process and the velocity obtained is compared with the measured experimental values [11]. Observations made through transmission electron microscopy on the welded interface between copper and aluminum revealed the ultrafine grain structures at the interface and an increase in dislocation density due to severe plastic [12].

The MPW machine consists of two circuits: a charging circuit and a discharge circuit (see Fig. 2). The charging circuit consists of a generator $(\mathrm{G})$ of very high voltage and a series of capacitor blanks (C) to store the electrical energy. The energy stored in the capacitor blank is given by

$E=\frac{1}{2} C V^{2}$

where $C$ is the capacitance and $V$ is the voltage of the discharge current.

The discharge circuit consists of an activation switch $(S)$, a coil, and the parts to be welded placed inside the coil. The stored energy is discharged though the discharge circuit by activating the switch and very high current of about 100 $200 \mathrm{kA}$ flows though the coil. Figure 3 shows a typical discharge current which is sinusoidal and exponentially decaying in nature.

The current flowing through the coil can be expressed as,

$I=I_{0} e^{\frac{t}{\tau} \sin (\omega t)}$

$I_{0}$ is the maximum current flowing through the circuit, the frequency and time period were given by $\omega=\frac{1}{\sqrt{L C}}$ and $\tau=2 \frac{L}{R}$, where $L$ is the total inductance of the circuit and $R$ is the total resistance of the circuit. A typical time period for the process is about $100-300 \mu$ s which makes the process suited for high-volume production in industry. Even though a very high current is used for the process, the shortoperation time keeps the total energy consumed to a minimum and reduces the cost per part in high-volume production. The current flowing through the coil produces a varying 
Fig. 2 Principle of magneticpulse welding

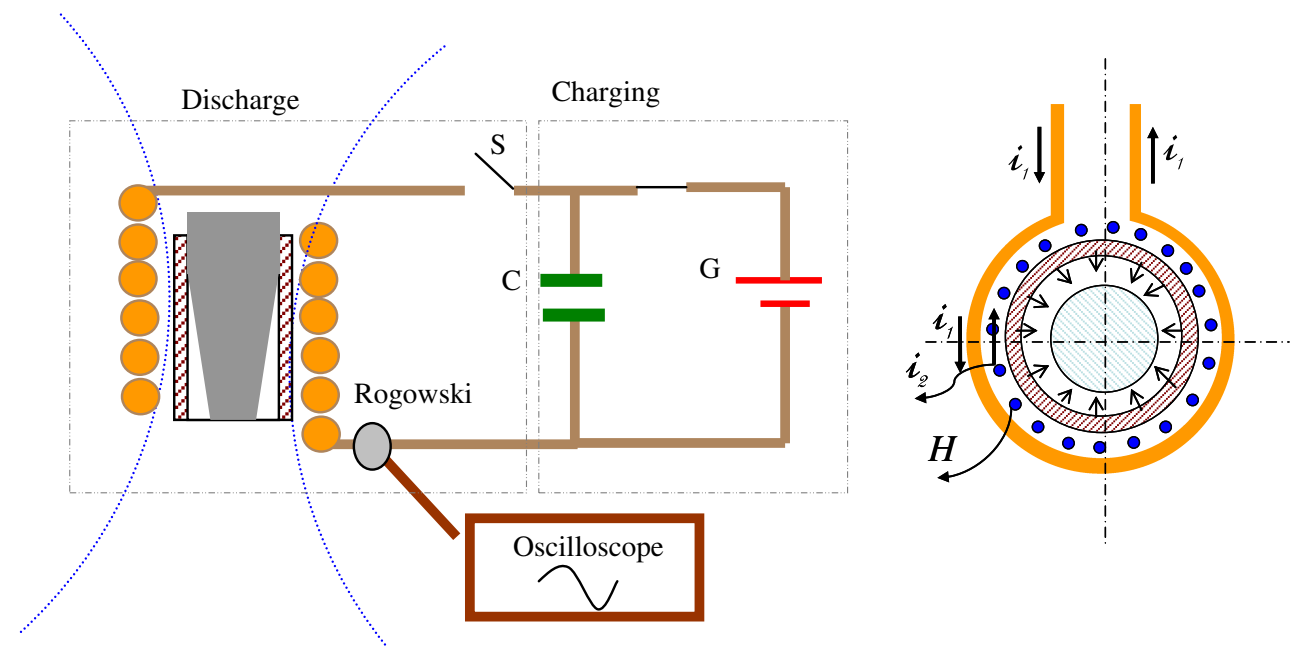

magnetic field around the coil and it induces a secondary current in the nearby conducting material. In MPW, the tubes to be welded are placed concentric to the coil and are isolated to avoid short circuit effects i.e., possible changes of current flow path. The induced secondary current flows through the surface of the outer tube and in turn produces a Lorentz force. This induced electromotive force (EMF) causes mechanical deformation of the cylinder and accelerates it to a very high speed in the range of 100 to $400 \mathrm{~m} / \mathrm{s}$ where subsequently, it impacts on the inner tube. The energy transferred due to the impact causes severe plastic deformation at the interface and metallurgical bonds are established between the parts. The depth of penetration of the induced current is influenced by the conductivity of the tube known as the skin effect and it can be evaluated using Eq. 3.

$\delta \simeq \frac{1}{\sqrt{\mu \pi f \kappa}}$

Where ${ }_{K}$ is the electrical conductivity of the tube, $\mu=4 \pi \times 10^{-7} N A^{-2}$ is the magnetic permeability and $f$ is the frequency of the discharge current. In the case of welding less-conducting material, aluminum cylinders are used on top as pushers to accelerate the outer tube. Use of thin cylindrical pushers could lead to loss of energy since the

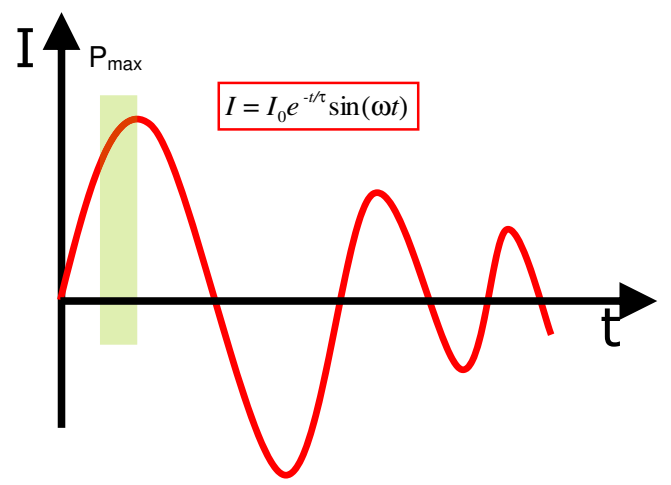

Fig. 3 Schematic representation of the discharge current entire induced EMF may not be captured and a thick launcher could lead to excessive energy being consumed for mechanical deformation of the pusher. Thus, a careful evaluation of skin depth is necessary to choose the size of the pusher.

The magnetic pressure $(P)$ acting is computed by integrating the EMF over the skin thickness and is represented as

$P=\frac{B^{2}}{2 \mu}$

where $B$ is the magnetic field density inside the coil.

The mechanical force acting on the cylindrical tube is computed from

$F=\frac{B^{2} S}{2 \mu}$

where $S$ is the surface area of the outer tube. From the principle of motion, the acceleration $\gamma$ of the tube can be expressed as

$\gamma=\frac{B^{2} S}{2 m \mu}$

where $m$ is the mass of the outer tube and the velocity of the tube $v$ can be approximated as

$v=\sqrt{\gamma \times d}$

where $d$ is the distance of travel by the tube.

For example, an 8-turn welding coil of diameter $23 \mathrm{~mm}$ can be made by winding a copper wire of $2.5 \mathrm{~mm}$ in diameter. A magnetic density of $17 \mathrm{~T}$ is measured for discharge energy of $9.73 \mathrm{~kJ}$. For an aluminum tube of $22-\mathrm{mm}$ diameter, $20-\mathrm{mm}$ long and $1 \mathrm{~mm}$ in thickness, from the above relations, the velocity is calculated as $207 \mathrm{~m} / \mathrm{s}$.

The expulsion of impurities and oxides on the surface takes place during impact; this phenomenon is known as jetting. Hence MPW does not require any special surface preparation. 
To aid jetting, the inner tube is tapered to an angle $\alpha$ and this causes variation of the travel distance of the outer tube along the length of the interface. The angle of impact seems to influence the quality of welding; for welding aluminum and copper, the metals were only welded at certain impact angles. Masumoto et al. reported that the plastic deformation of the aluminum tube is initiated at about $16 \mathrm{kA}$ of current. Indentation due to impact is observed on inner tubes made of aluminum and other dissimilar materials for currents of 40-50 kA. They observed partial or complete welding for discharge currents above $54 \mathrm{kA}$ [13]. Rupture of joints takes place whenever large discharge energy is used and the formation of voids due to melting has been reported by several researchers (see Fig. 4). Hence, it is important to estimate the rise in temperature along the interface during the process and the influence of different process parameters on the quality of the weld. In the present study, the application of magnetic-pulse welding to the bimetallic welding of aluminum and copper is carried out and the aspect of wave formation, temperature, and intermetallic phase in the welded part is investigated. Intermetallic phases formed in the welded zone are analyzed using scanning electron microscopy and energy-dispersive x-ray spectrometry (EDS). MPW is demonstrated for welding of ODS alloy.

\subsection{Bimetallic joint: aluminium and copper}

\subsubsection{Material and experimentation}

Magnetic-pulse welding experiments were carried out using a generator with a maximum energy of $12 \mathrm{~kJ}$ and it has a series of six capacitors each of capacitance $60 \mu \mathrm{F}$. The inductance of the generator is $0.5 \mu \mathrm{H}$. The dimensions of the part to be joined are shown in Fig. 5. The outer tube was fabricated from 1,100 aluminum alloy and it was machined to an outer diameter of $15 \mathrm{~mm}$ and wall thickness of $1 \mathrm{~mm}$. The inner tube was made of pure copper alloy and was tapered to an internal angle of $9^{\circ}$ and discharge energy of $5 \mathrm{~kJ}$ was employed. A small gap of $0.85 \mathrm{~mm}$ was provided between the copper and the aluminum tube so that the

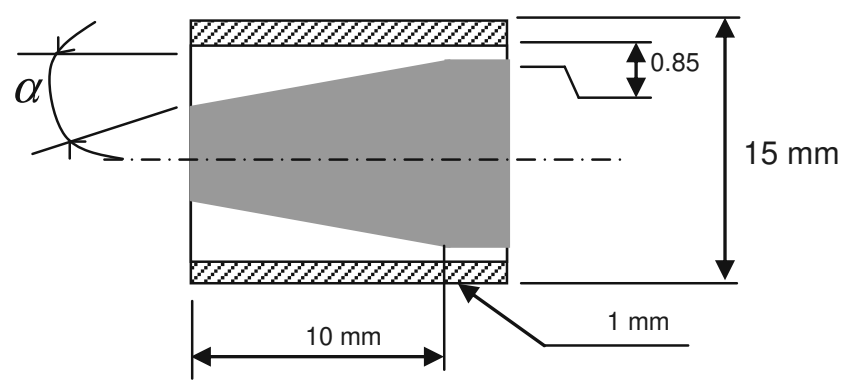

Fig. 5 Dimensions of the welded $\mathrm{Al} / \mathrm{Cu}$ parts

aluminum tube has time for acceleration before the first point of impact.

The welded sample was then tested using a simple mechanical peeling test of the outer tube. After confirmation of welding, the welded joint was cut along the length of the axis and was subjected to mechanical polishing to $1-\mu \mathrm{m}$ size. Metallographic examination of the welded surface was carried out on a Nikon eclipse LV150 optical microscope and JOEL JSM-6060A scanning electron microscope (SEM). Chemical etching of the samples was not carried out since the observation of micro structure at the welded surface is not considered for this study. Chemical composition mapping at the welded interface was obtained though EDS analysis at the interface between the copper and aluminum, to study the formation of intermetallic phases.

\subsubsection{Results and discussion}

During mechanical peeling, cracking, and decohesion of the interface takes place for about $2-3 \mathrm{~mm}$ at the start and end of the interface. This suggests that the welding has not taken place over the entire length of the sample. Figure 6 shows the images of optical microscopy observations along the length of the interface. The presence of several distinct zones can be identified. The interface at the beginning of the weld (shown in Fig. 6a), where the metals were in contact, shows that welding has not taken place. This was followed by the middle region Fig. 6b, where the wavy pattern typical to that
Fig. 4 Scanning electron images showing micro-voids on a peeled aluminum surface [14]
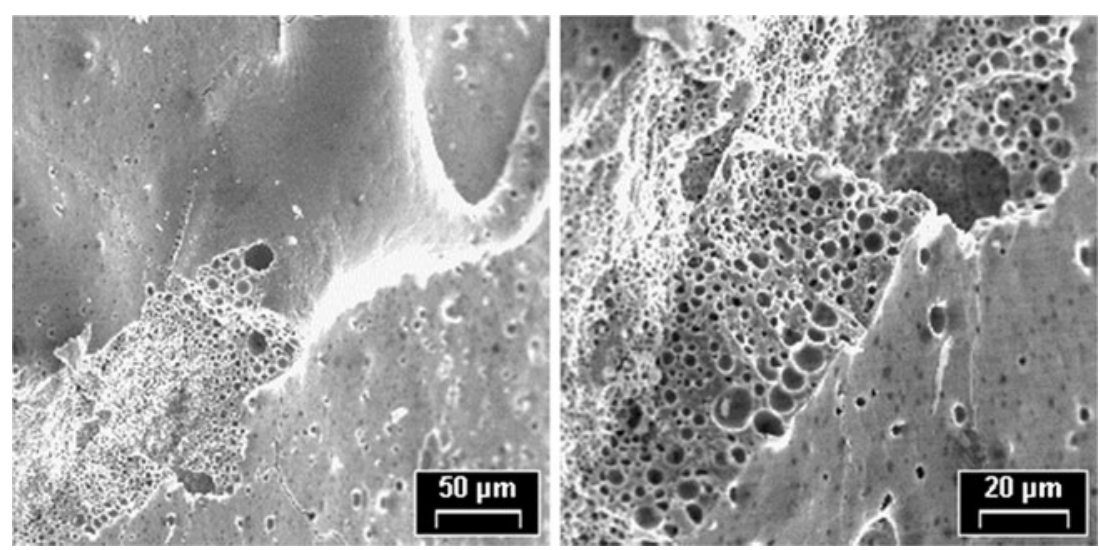
Fig. 6 Optical microscopy images of the $\mathrm{Al} / \mathrm{Cu}$ interface

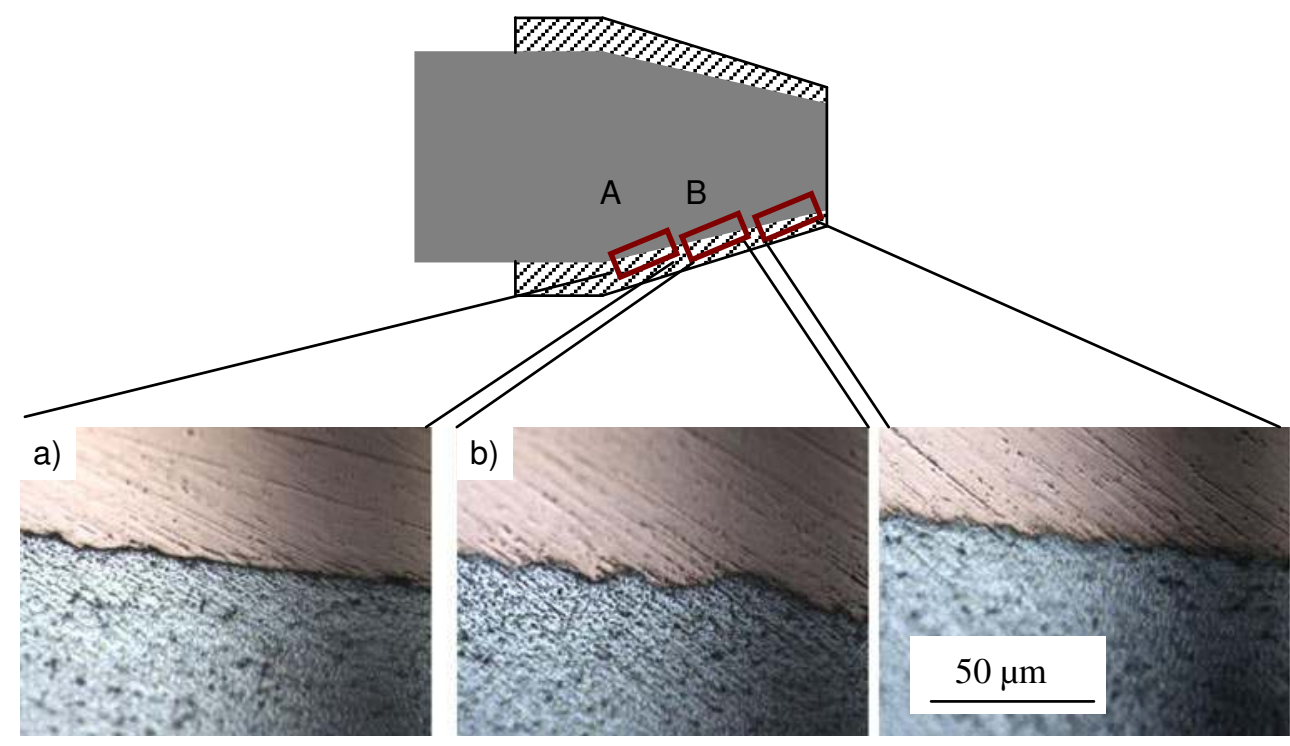

is about $10-20 \mu \mathrm{m}$ and it is not evenly distributed along the length of the interface. Figure $7 \mathrm{c}$ shows the formation of the intermetallic phase in the crest of the interface wave patterns. Thus, the formation could have been influenced by surface cracking, mixing, and interpenetration of one metal in the other. However, it is not sure whether this transition zone formed due to heating and melting of the material or just due to extreme stain hardening of the interface at high-velocity impact. In Fig. $7 \mathrm{~d}$, the presence of micro porosity and holes was detected in the intermetallic layer at the end of the welded zone, where the velocity of impact was very high. This could have been the result of melting and rapid cooling of the intermetallic layer.
Fig. 7 Scanning electron images of $\mathrm{Al} / \mathrm{Cu}$ interface
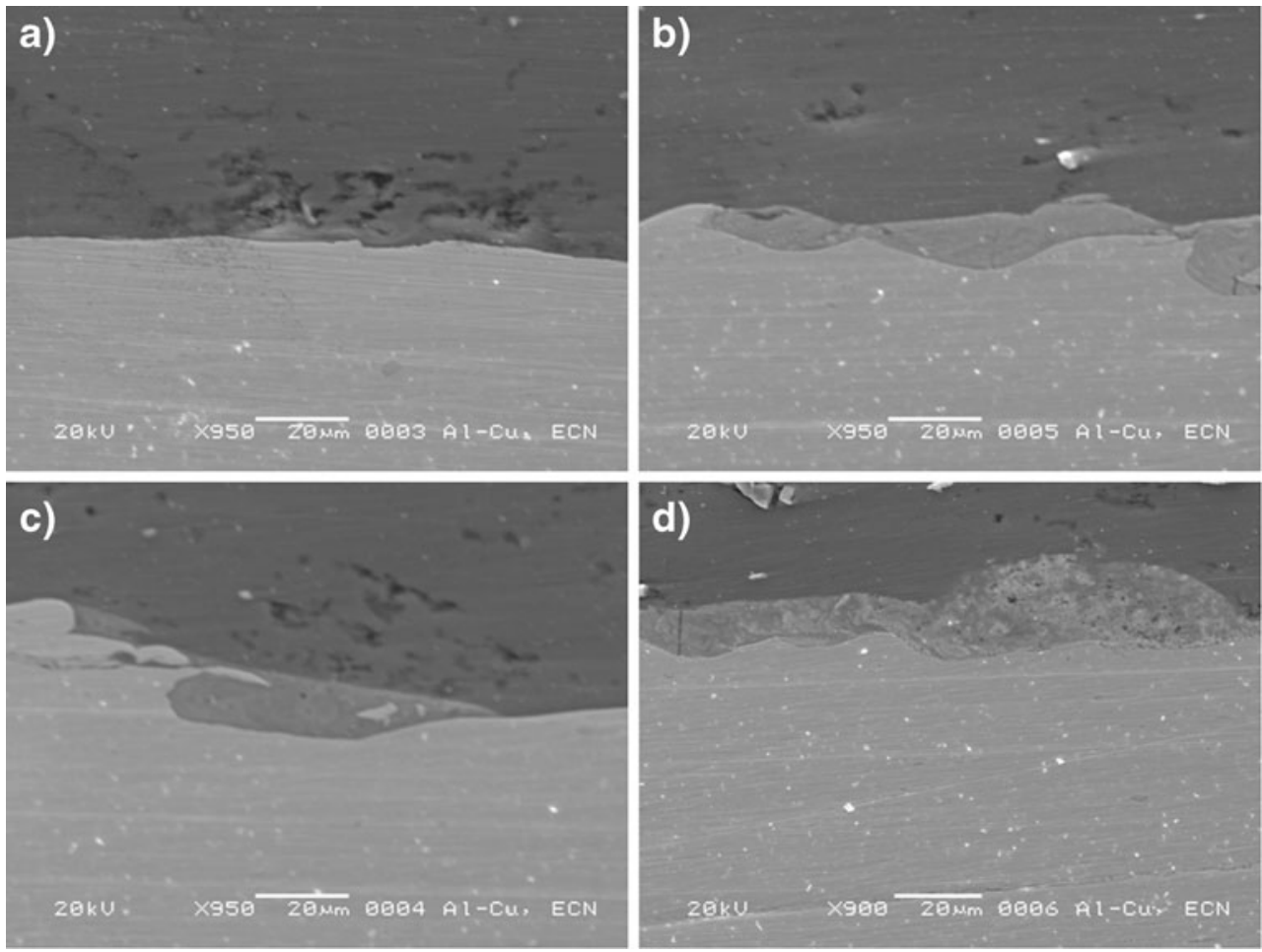
X-ray dot mapping and energy-dispersive spectral analysis was carried out in the zone where the formation of inter metallic phase was observed (shown in Fig. 8a). Figure 8b shows the chemical composition of the interface micro constituent observed in the location as indicated in Fig. 8a. Results from energydispersive spectroscopy demonstrate that aluminum and copper did not take an equal part in the intermetallic formation, a chemical composition of 67.5 at.\% aluminum and 32.1 at.\% copper was found. Comparison of this result with the aluminum-copper phase diagram shown in Fig. 1 strongly implies that transition region must be the ambient-temperature nonstochiometric $\mathrm{CuAl}_{2}$ phase. The x-ray dot mapping of the interface shown in Fig. 8c and d, corresponds to the presence of copper and aluminum concentration in the zone of interest. The intermetallic zone formation could be a direct result of atomic diffusion of one metal into the other and its formation can be accelerated with an increase in temperature $[15,16]$. Hence, it should be clearly understood from the thermodynamic aspect of the material and the kinematics of transfer of energy between the metals. It is essential to quantify the growth of the intermetallic zone since the formation of a large zone could cause brittle fracture along the welded zone and the depth of diffusion could exponentially increase as a function of temperature and time. Of all the intermetallic phases in the aluminum-copper phase diagram, the $\mathrm{CuAl}_{2}$ phase exhibits the most negative heat of formation, indicating a particularly strong exothermic reaction [17], and therefore increases the chemical driving force for the formation of a 2:1 aluminum-copper compound.

\subsubsection{Wave formation at the interface}

From the optical and scanning electron images, it is evident that the wave formation was more pronounced in the mid region than the beginning and end of the welded interface, where the bonding and formation of inter metallic phases had been observed. This wave formation is similar to that one observed in explosive welding and the associated mechanisms could be related. Allen et al. reported the formation of surface jetting during the oblique impact of hard steel plates on soft zinc surfaces [18]. Subsequently, the mechanism of wave formation has been studied and its influence on the process has been investigated. Wantanabe and Kumai studied the interface morphology in magnetic-pulse welding of aluminum/aluminum plates and copper/copper plates [19]. The variation of wave length along the length of the weld is caused due to the variation of collision angle between the flyer plate and the parent material. Also, the formation of maximum amplitude and wave length at the interface tends to increase with the increase in measured impact velocity and estimated the magnetic pressure acting on the interface. Ben-Artz et al. studied the wave formation mechanism based on the shock wave propagation in the parent material [20]. They proposed an empirical relationship relating the wavelength and the distance traveled by the shock wave inside the inner tube. The mechanism for the formation of waves was explained on the basis of interaction
Fig. 8 Electron dispersive analysis of a Interface between aluminum and copper, $\mathbf{b}$ Inter metallic chemical composition, c electron dot mapping of copper, and $\mathbf{d}$ electron dot mapping of aluminum
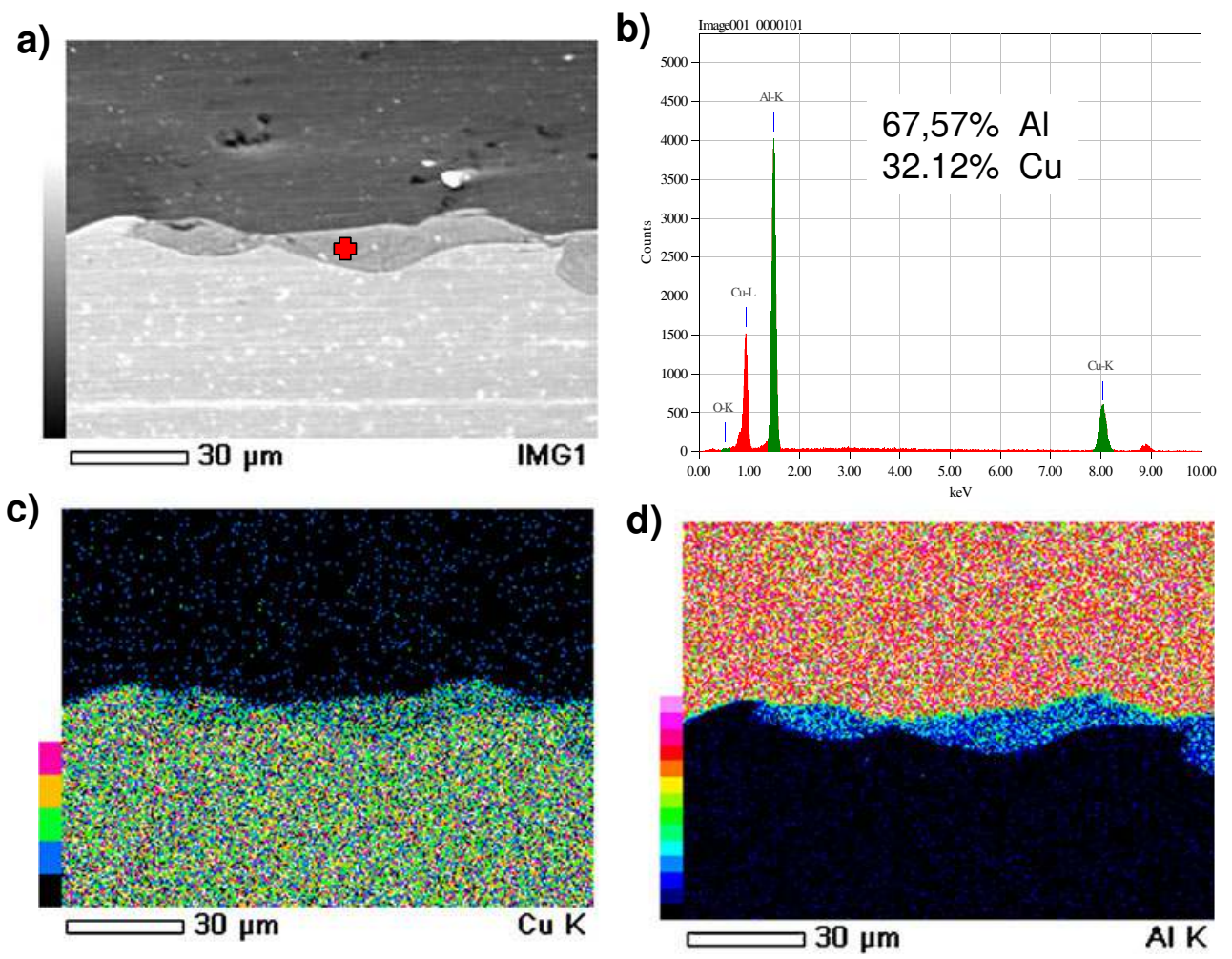
Fig. 9 3D x-ray

microtomography analysis of the copper-aluminum weld interface

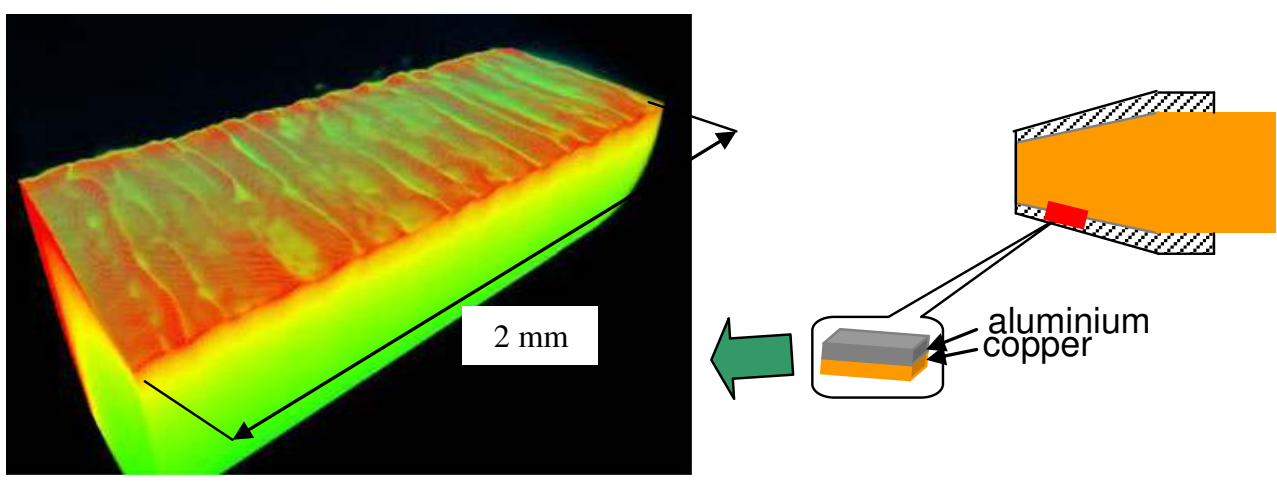

between the surface and returning secondary wave from inside the tube. To validate this explanation, they carried out experiments with inner tubes of varying wall thickness and at different energy levels.

In order to investigate the wave morphology, a thin slice of the interface of $1 \mathrm{~mm}$ in width and $2 \mathrm{~mm}$ in length as shown on the right of Fig. 9 were cut from the middle region. The middle region was chosen, since the wave formation was predominant and the inter metallics were observed in this region. This small volume was $\mathrm{x}$ ray scanned in a microtomography machine to construct a 3D image of the interface. A 3D view of the wave morphology is shown in Fig. 9 and observation of the surface morphology shows that the wave patterns were uniform along the angular direction (axi-symmetric). Even though the pixel accuracy of the reconstructed image is less than $1 \mu \mathrm{m}$, it is not possible to clearly distinguish the presence of an intermetallic layer on the welded surface through tomographic analysis. Figure 10 shows the projection of interface wave from the 3D-scanned image from which

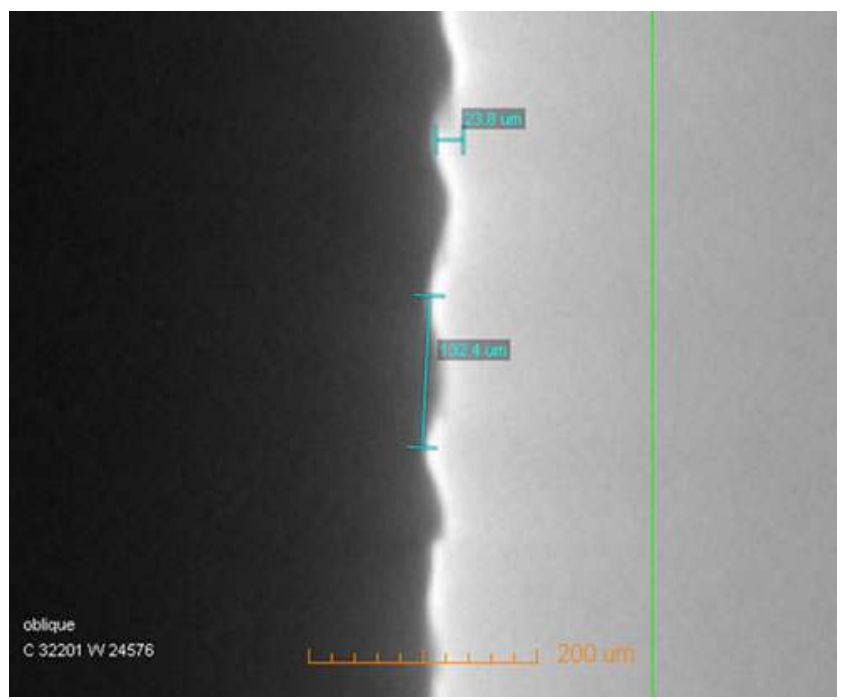

Fig. 10 2D projection of the copper-aluminum weld interface showing a wavy pattern the wave length of $132.4 \mu \mathrm{m}$ and the amplitude of $23.8 \mu \mathrm{m}$ are measured.

\subsubsection{Influence of impact velocity on temperature}

Experimental evaluation of temperature during the magnetic-pulse welding process is very difficult because of the high speed process involving a very high energy. Komelkov proposed a simple model where the increase in interface temperature $(\Delta T)$, was related only to the maximum amplitude of magnetic field $B_{\max }$ :

$\Delta T \approx 0.34 \times B_{\max }^{2}$

Based on this model, the increase in temperature is of the order of $100{ }^{\circ} \mathrm{C}$ even in cases of welding at a highenergy level [21]. However, the reported melting of metals along the interface suggests otherwise; thus, a better model to predict the rise in temperature is required. In the present study, a model to predict the temperature
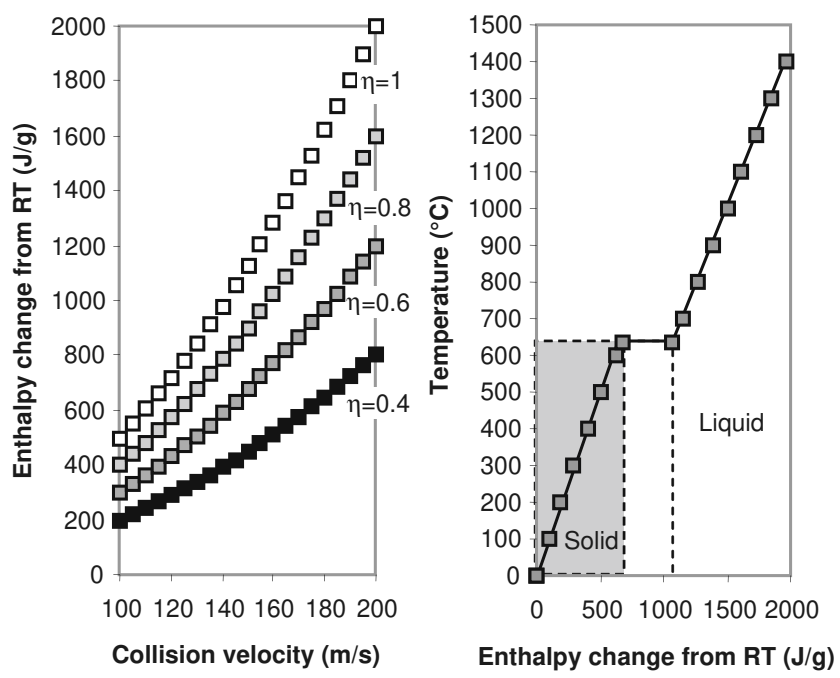

Fig. 11 Change in enthalpy as a function of impact velocity for different efficiency factor and the increase in temperature corresponding to the change in enthalpy 

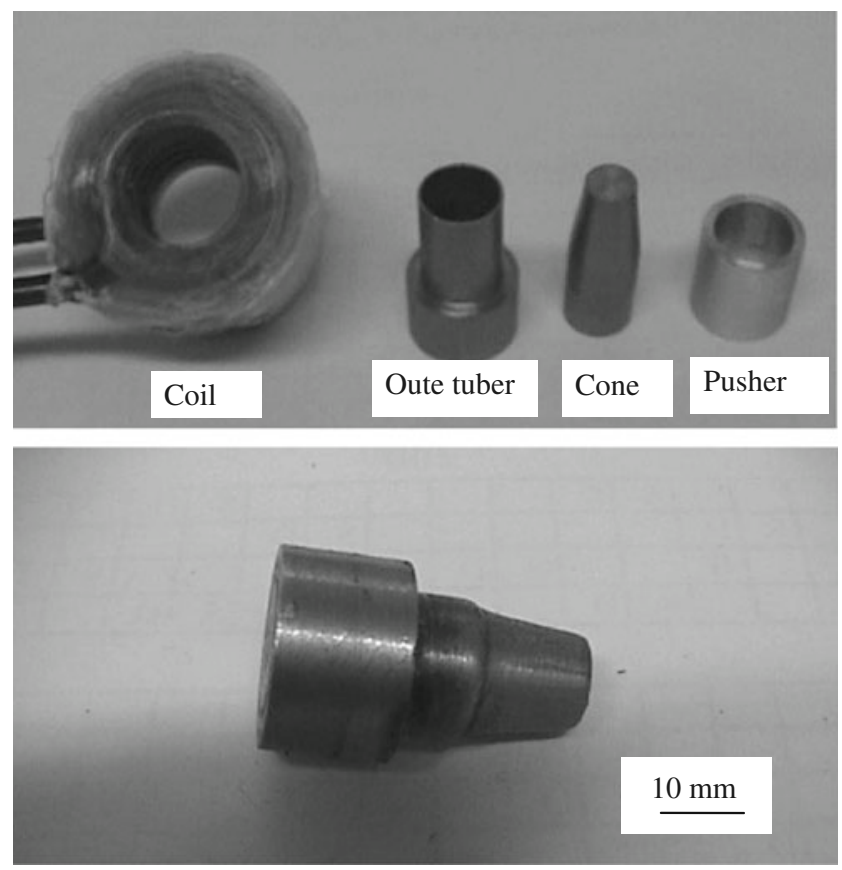

Fig. 12 The ODS parts along with the coil and pusher are shown on top and the welded specimen on the bottom of the image

based on the energy balance between the transferred kinetic energy and the enthalpy in the system is discussed. In MPW, the welding is caused by the high-velocity impact of the outer tube with the inner tube. The kinetic energy of the outer tube is transferred at the point of impact to the inner tube and changes the enthalpy in the surrounding mass. Considering adiabatic heat transfer, the simple balance of energy can be expressed by the conservation law as shown below

$\frac{1}{2}\left(\rho_{1} A t_{1}\right) V_{1}^{2} \eta=\rho_{2} A t_{2} \Delta H$

where $\rho_{1}$ and $\rho_{2}$ are the density of the outer and inner tube and $A t_{1}$ and $A t_{2}$ are the atomic weight of the inner and outer tube, respectively. $V_{1}$ is the velocity of impact of the outer tube on the inner one, $\Delta H$ the change in enthalpy in the system, and $\eta$ is the efficiency factor based on the ratio of conversion of kinetic impact energy in to heat at the interface. Considering that the change in energy causes heating of the system, the rise in temperature can be quantified as shown below

$\Delta H=\int_{298 K}^{T} C_{p} d T+\left(\Delta h_{f}+\int_{T_{m}}^{T} C_{p} d T\right)_{T \geq T_{m}}$

Where $\mathrm{C}_{p}$ is the average specific heat, $\Delta h_{f}$ is the change in enthalpy due to fusion, and $T_{m}$ is the melting temperature of the metal. Considering the outer tube as aluminum and the inner tube as copper and using Eq. 9, the change in enthalpy as a function of impact velocity is plotted for different efficiency factors (see Fig. 11) and the calculated enthalpy changes the rise in temperature is evaluated using the relation Eq. 10. From the graph, for an efficiency factor of 0.8 , the upper-cut off limit for the velocity can be fixed at $170 \mathrm{~m} / \mathrm{s}$. An experimental value of $13 \mathrm{~T}$ is measured for the discharge energy of $5 \mathrm{~kJ}$ and if the travel distance of the outer projectile is taken as $1 \mathrm{~mm}$, a velocity of $158 \mathrm{~m} / \mathrm{s}$ is obtained from the expressions (Eqs. 6 and 7). Using Fig. 11, the change in enthalpy in the aluminum could be anywhere between 400 and $1,300 \mathrm{~J} / \mathrm{g}$ depending upon the value of efficiency factor and the rise in temperature could be between 250 and $900{ }^{\circ} \mathrm{C}$. The chance of the efficiency factor being close to one is higher than close to zero.

\section{Welding of ODS alloy}

Innovation in materials technology has lead to the creation of advanced materials by combining the known metals with other non-metallic particles, known as metal matrix composites (MMC's) and ODS alloys. ODS alloys could be of nickel or steel alloy base reinforced with oxide particles usually less than $2 \%$. Steel-based ODS alloys are being developed for
Fig. 13 Interface between the welded sample for the ODS alloy a Initial impact zone, b Intermediate zone, and $\mathbf{c}$ Weld region a)

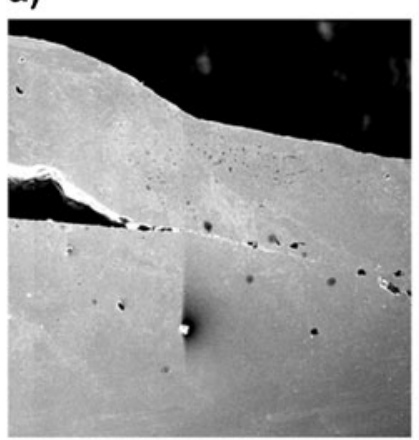

b)

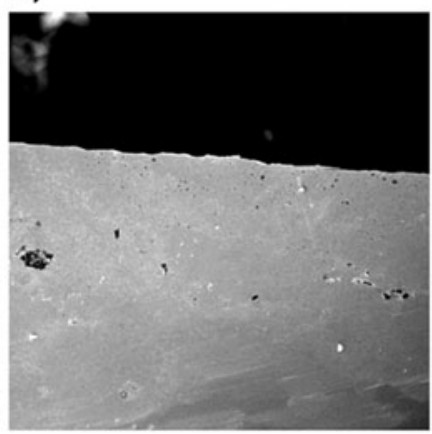

c)

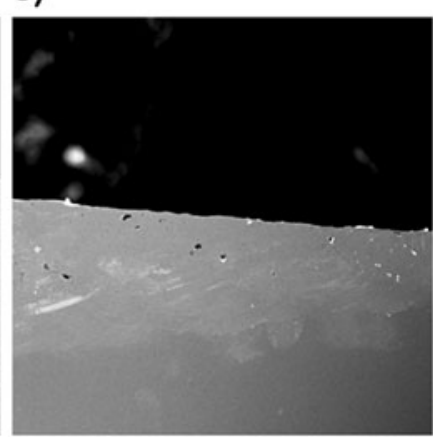

500 microns 
Fig. 14 Schematic representation of the dynamic compaction system a) Axi-Symmetric

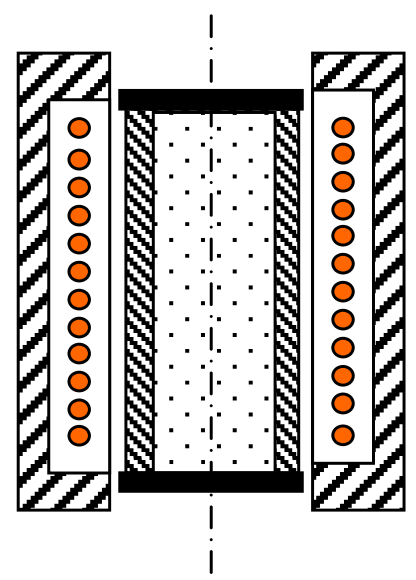

b) Uni-axial

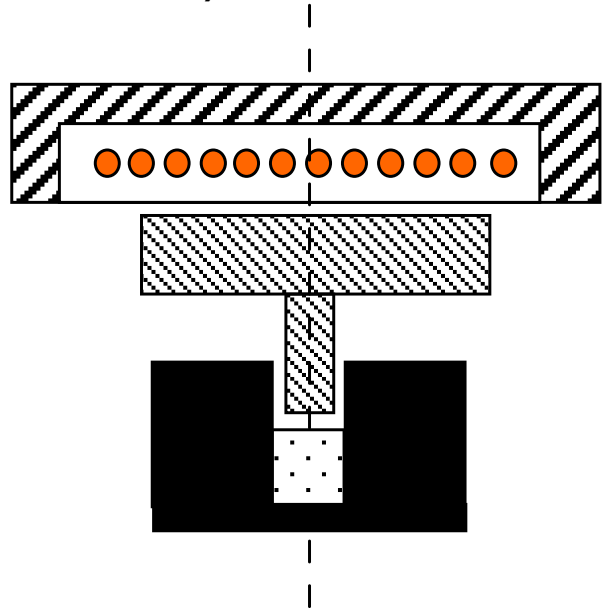

high-temperature applications. But their application is hindered due to the lack of suitable manufacturing route, and specifically for joining. The welded joint should have hightemperature creep strength and the process should not alter the reinforcement structure and to some extent, the microstructure of the base material. Welding by fusion leads to considerable damage to the reinforcement structure such as particle agglomeration and also, significantly changes the alloy microstructure. The entrapped gases during the fabrication of ODS alloy could cause the formation of porosity during fusion welding. Solid-state welding these materials becomes an obvious choice and several techniques such as friction welding, friction-stir welding, and diffusion bonding have been tried. Inkson and Threadgill investigated the friction welding of ODS alloys and observed the welded samples using a transmission electron microscope (TEM) [22]. The TEM observations revealed distinct micro-structural zones with different grain size and the agglomeration of the particles. Mathon et al. studied the micro-structural evolution in friction-stir welding of PM2000 ODS alloys and found that the average particle size in the welded zone is larger than the parent alloy [23]. Residual stresses determined by neutron diffraction showed an increase of the residual stresses in the weld zone and it is more pronounced in the direction of welding than in the transverse direction.

MPW could be an ideal process to weld ODS alloy for applications such as nuclear-reactor cladding tubes. Since ODS alloys are less-conducting materials, the acceleration of the tube was carried out using an aluminum pusher and this demands a very high-energy level. The ODS alloy used in the present study was fabricated by mechanical alloying of high chrome ferritic steel $(18 \% \mathrm{Cr})$ with nanometric $\mathrm{Y}_{2} \mathrm{O}_{3}$ particles $(0.5$ vol.\%) and then the alloyed powder was compacted through hot extrusion. The magnetic-pulse welding of the ODS alloy was carried out using a generator with a capacitance of $272 \mu \mathrm{F}$, and a maximum energy level of $30 \mathrm{~kJ}$. An outer tube of $10 \mathrm{~mm}$ in diameter and $0.5 \mathrm{~mm}$ thickness and an inner cone with an inclination angle of $8^{\circ}$ was machined from the extruded cylindrical rod. The cone was placed inside the tube and the assembly was fixed using a fixture to arrest the movement during impact. A 6-turn solenoid coil of diameter $13.6 \mathrm{~mm}$ was made using a wire of $2.5 \mathrm{~mm}$ diameter for the experiment. Figure 12 shows the parts used for welding along with the coil and pusher used

Fig. 15 Dynamic compaction system used for the experiments

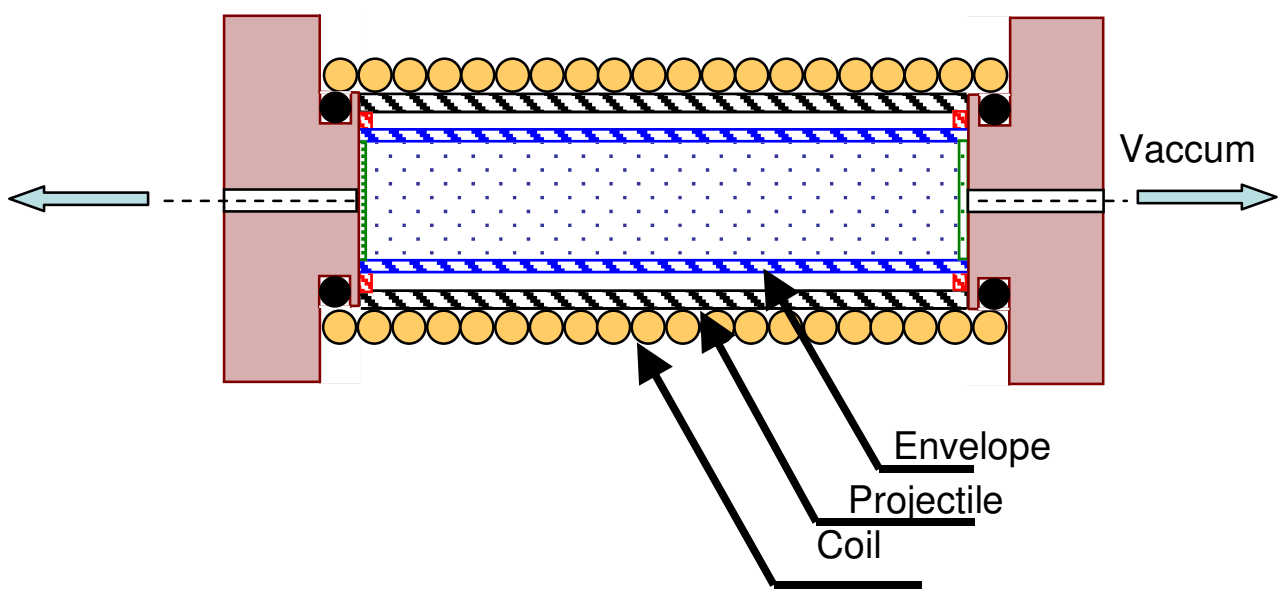



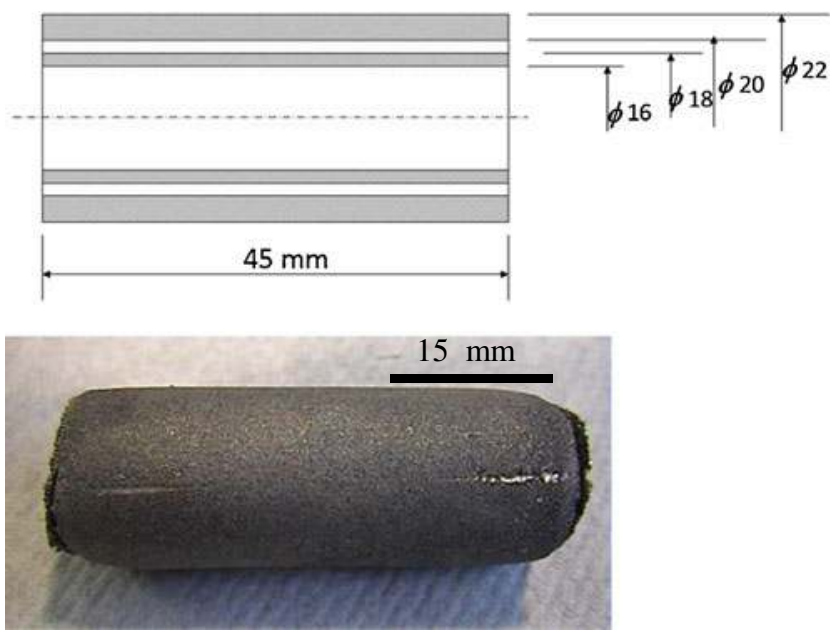

Fig. 16 Dimension of the projectile and the envelope are shown on the top and the compacted sample is shown below

for the experiment. A discharge energy of $14 \mathrm{~kJ}$ was discharged through the coil and the welded specimen (on the bottom of Fig. 12) was subjected to mechanical-peel testing to confirm bonding.

Secondary electron images of the welded ODS alloy shown in Fig. 13 reveals three distinct regions of the interface (a) an initial impact zone, (b) an intermediate zone, and (c) a weld region. In the initial impact zone, the parts were in contact with a deep crack. As we move away, the wavy morphology was observed along the interface in the intermediate zone which was visible during microscopy observation and was followed by the welded region where the interface was almost invisible during SEM observations. This confirms the bonding in this zone and also corresponds to the results observed in the mechanical peeling test. However, the analysis of structural modification of the dispersed

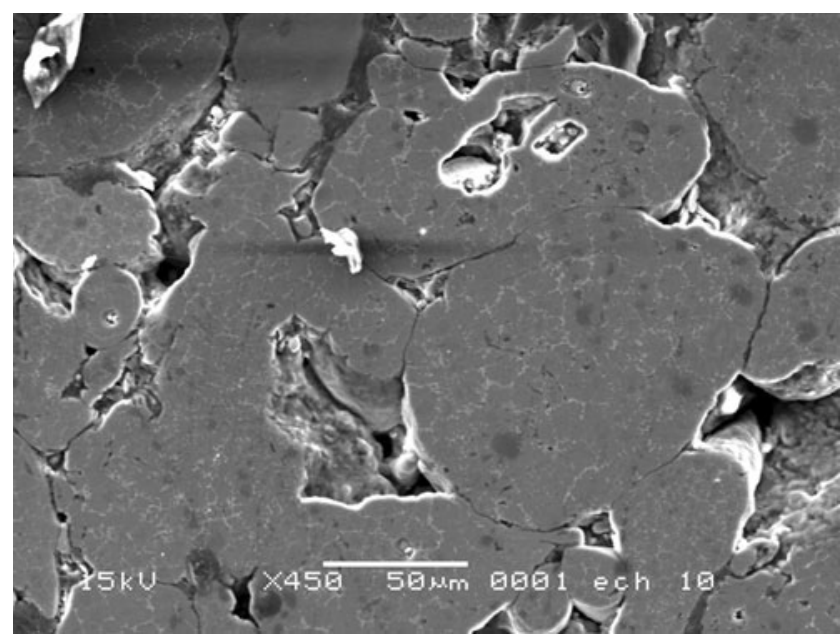

Fig. 18 Scanning electron microscopy image at the axis center of the aluminum-compacted sample

yttrium oxide along with the variation of the microstructure of the base metal requires further investigations and the service quality of the weld for high-temperature creep applications should be verified through elevated temperature pressure test and thermal cycling tests.

\section{Magnetic-pulse compaction of powders}

In magnetic-pulse compaction (MPC), the projectile accelerated by electromagnetic forces is used to compress the powders placed inside a die. Electromagnetic energy permits consolidation of powders at very high velocity close to the theoretical density of the powder and a very good aspect ratio of the specimen is possible when compared to conventional compaction. Compaction can be achieved without causing
Fig. 17 Measurement location and corresponding value of porosity for the compacted sample
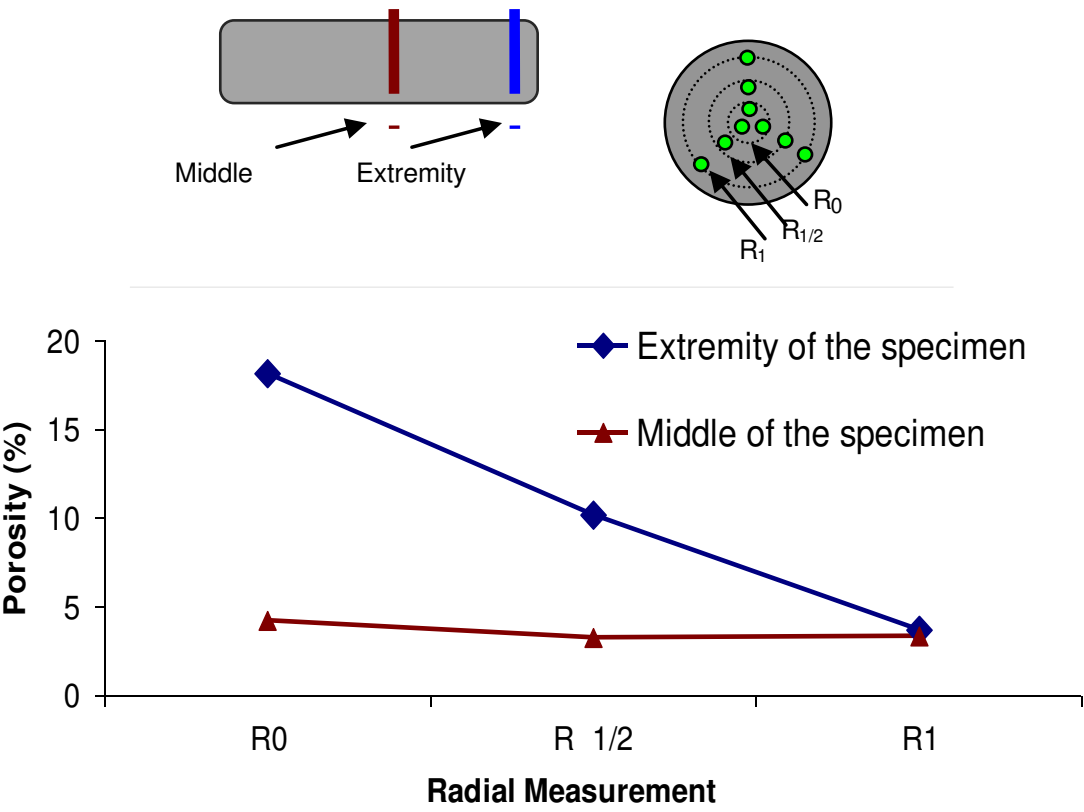
significant heating to the powder material. Based on the direction of compression, the process can be classified as iso-dynamic and uni-axial as shown in Fig. 14 [24]. In the iso-dynamic condition, the compaction of the powder is effected in the radial direction. The powder material is enclosed in a conducting tube placed inside a cylindrical coil. The discharge of the energy stored in the capacitor bank through the coil causes the same sequence of events as in magnetic-pulse welding. An electromagnetic shock wave passes through the powder and results in compaction of very high density. Preheating of powder can be carried out by placing a furnace adjacent to the compaction coil. In the uniaxial system, the powder is filled in a die and the piston is accelerated using electromagnetic forces generated due to a high-energy discharge through the coil placed adjacent to it. Very little work has been carried out in the iso-dynamic compaction of powders and in the present study, a compaction system to realize cylindrical part is presented.

Kononenko et al. investigated the kinetic densification ratio for iron powders placed inside the thin tubes made of copper and aluminum with different wall thicknesses [25]. They concluded that aluminum could better serve in cases of thick wall applications. Baccino et al. demonstrated the use of a projectile to compact the powders placed inside an envelope and its use increases the velocity of deformation of the powder when compared to the direct compaction [26]. Chelluri performed compaction of a tungsten steel composite; after preheating the powder at $1,000{ }^{\circ} \mathrm{C}$ and subjecting the compaction to multiple compaction cycles, compaction close to $99 \%$ of the theoretical density of the alloy was produced [27]. Popov et al. produced MMC with aluminum base and silicon carbide reinforcement through dynamic consolidation of mechanically alloyed composite powders [28]. They managed to produce sound composite materials with a homogenous distribution of reinforcement particles and the hardness of the materials seems to increase with an increase in the milling time.

In the present study, the compaction system as shown in Fig. 15 was used for the experiments. It consists of a cylindrical projectile placed inside the coil and an envelope filled with power particles placed inside the projectile. The envelope was closed using end caps with a provision to create a vacuum. Energy of $9.72 \mathrm{~kJ}$ was discharged through a two-layered solenoid coil made of $2 \mathrm{~mm}$ diameter wire. The projectile and the envelope made of aluminum were placed inside the coil. The coil dimensions are shown in Fig. 16. Discharge of high energy though the coil creates a Lorentz force and accelerates the projectile where it impacts with very high pressure on the envelope, resulting in compaction of the powder. The projectile and the envelope were then cut open to retrieve the compacted specimen. The length of the coil was made long enough to have a uniform distribution of magnetic pressure along the length of the compact and the end caps were made of non conducting materials in order not to modify the magnetic field profile. A small gap was provided between the projectile and the envelope so that the projectile will gain sufficient velocity before impact on the envelope. The thickness of the projectile was calculated based on the skin thickness in the conductor (Eq. 3 ) and the envelope was made thick enough to avoid wrinkling due to compaction.

The compact produced had sufficient strength for mechanical cutting. The compact was cut in the middle and at the extremity for metallographic observations, as shown in Fig. 17. The cut surfaces were mechanically polished and subjected to optical microscopy observation. The quality of the compact is quantified by measuring the porosity using a pixel classifier. Variation of porosity along the radial direction was measured at three different angular positions and the representative mean value was taken as reference. The variation of porosity along the radial and axial direction for the compact produced is shown in Fig. 17. The measured porosity values indicate that the specimens were better compacted on the outer surface than along the axis center. A high value of $18 \%$ porosity was observed at the axis center on the extremity of the specimen. Scanning electron microscopy observation of the cut surface is shown in Fig. 18. The particle was subjected to severe deformation and intimate contact was established between the particles. The observation shows the existence of porosity between particles and does not reveal the diffusion of material between particles. The compacts could be further densified through either hot extrusion or sintering to achieve full strength.

\section{Summary}

The application of electromagnetic energy for welding and powder compaction is investigated in the present study. The results suggest that magnetic-pulse welding technology can be used to produce high-quality welds between dissimilar metals and advanced materials such as ODS alloys. The formation of an intermetallic phase is observed along the interface in the welded aluminum and copper sample. Chemical analysis carried out through energy-dispersive spectra analysis suggest that the observed inter metallic phase could be $\mathrm{CuAl}_{2}$. The model relating the impact velocity to the interface temperature predicts a significant increase in temperature between 250 and $900{ }^{\circ} \mathrm{C}$ based on the choice of efficiency factor. The formation of intermetallic phases could be accelerated and melting of metals is possible when a very high energy is applied during welding. A good quality weld is produced for the ODS alloy, however, the service quality of the weld for high-temperature creep applications and modification caused to the reinforced $\mathrm{Y}_{2} \mathrm{O}_{3}$ particles at the interface should be verified. Magnetic-pulse compaction of cylindrical parts was realized using aluminum powder and the measured porosity values indicate that the specimen is 
better compacted on the outer surface than along the axis center.

Acknowledgments The author would like to thank Dr. Christian Burtin for helping to carry out $\mathrm{x}$-ray tomography analysis. The author would also like to acknowledge the funding received through project AMETIS and the participating institutions.

\section{References}

1. Murray JL (1990) Binarry Alloy Phase Diagrams. American Society for Metals

2. Akbari-Mousavi SAA, Barrett LM, Al-Hassanib STS (2008) Explosive welding of metal plates. J Mater Process Technol 202:224-239

3. Kochan A (2000) Magnetic pulse welding shows potential for automotive applications. Assem Autom 20(2):129-132

4. Shribman V (2001) Take advantage of the new magnetic pulse welding process. a welding review. Svetsaren Weld Rev 56(2-3):14-16

5. Brown WF, Bandas J, Olson NT (1978) Pulsed magnetic welding of breeder reactor fuel pin end closures. Weld J 57(6):22-26

6. Khrenov KK, Chudakov VA (1978) The formation of welded joints in the magnetic pulsed welding of cylindrical workpieces. Weld Prod (USSR) 25(9): 19-20

7. Stern A, Aizenshtein M (2002) Bonding zone formation in magnetic pulse welds. Sci Technol Weld Join 7(4):339-342

8. Marya M, Marya S, Priem D (2009) Springer Handbook of Mechanical Engineering, volume 10, chapter Fundamentals of Magnetic Pulse Welding for the fabrication of dissimilar material structures, pages 723-732.

9. Aizawa T, Kashani M, Okagawa K (2005) Application of magnetic pulse welding for aluminum alloy and steel sheet joints. Welding in the World 49:212-222

10. Kore SD, Date PP, Kulkarni SV (2007) Effect of process parameters on electromagnetic impact welding of aluminium sheets. Int $\mathrm{J}$ Impact Eng 34:1327-1341

11. Zhang Y, Daehn G, Eplattenier PL, Suresh Babu S (2009) Experimental study and numerical simulation on magnetic pulse welding for pre-flanged aa6061-t6 and cu101 sheets. Proceedings of 8th International conference on Trends in Welding Research, pages 715-720

12. Zhang Y, Suresh Babu S, Daehn GS (2010) Interfacial ultra finegrained structures on aluminium alloy 6061 joint and copper alloy 110 joint fabricated by magnetic pulse welding. J Mater Sci 45:4645-4651

13. Masumoto I, Tamaki K, Kojima M (1985) Electromagnetic welding of aluminum tube to aluminum or dissimilar metal cores (study on electromagnetic welding, report 1). Trans Japan Weld Soc 16(2):110 116

14. Marya M, Marya S, Priem D (2005) On the characteristics of electromagnetic welds between aluminum and other metals and alloys. Weld World 49:74-84

15. Wakeman DW (1954) American Chemical Society Monograph Series. Reynolds Publishing

16. Gorecki T and Michno Z 1983 Proc. Conf. 'Dimeta 82', Tihany, Hungary (1982) (Diffusion and Defect Monograph Series no 7) ed F J Kedves and D L Beke (Switzerland: Trans. Tech. Publications) p 365

17. Hultgren R (1970) Selected Values of the Thermodynamic Properties of Binary Alloys. American Society for Metals

18. Allen WA, Mapes JM, Wilson W0 (1954) An effect produced by oblique impact of a cylinder on a thin target. J Appl Phys 25:675676

19. Wantanabe M, Kumai S (2009) Interfacial morphology of magnetic pulse welded aluminum/aluminum and copper/copper lap joints. Mater Trans 50(2):286-292

20. Ben-Artz A, Stern A, Frage N, Shriban V, Sadot O (2010) Wave formation mechanism in magnetic pulse welding. Int J Impact Weld 37(4):397-404

21. Komelkov VS (2010) A technology for high-pulsed currents and magnetic fields. Atomizdat

22. Inkson BJ, Threadgill PL (1998) Friction welding of FeAl40 grade 3 ODS alloy. Mater Sci Eng, A 258(1-2):313-318

23. Mathon MH, Klosek V, de Carlan Y, Forest L (2009) Study of PM2000 microstructure evolution following FSW process. Journal of Nuclear Materials, 386-388:475-478. Fusion Reactor Materials, Proceedings of the Thirteenth International Conference on Fusion Reactor Materials

24. Mamalis AG, Manolakos DE, Kladas AG, Koumoutsos AK (2004) Electromagnetic forming and powder processing: trends and developments. Appl Mech Rev 57(4):299-324

25. Kononenko VV, Levina DA, Raichenko AI (1975) Electromagnetic compression of a conducting tube filled with powder. Acad Sci USSR 145:30-33

26. Baccino R, Rarayre C, David R (1987) Le magnéto compactage de poudres: obtenir des matériaux inédits (Magnetic compaction of powders : to obtain non-conventional materials). Magnétoformage : des applications, 58/RGE(9)

27. Chelluri B (1994) Dynamic magnetic consolidation (DMC) process for powder consolidation of advanced materials. Mater Manuf Process 9(6): 1127-1142

28. Popov VA, Aksenov AA, Ivanov VV, Lesuer DR, Gulbin VN, Kobelev AG, Solonin AN, Paranin SN, Khodos II, Smirnov OM, Zayatas SV (2002) MMC production method using dynamic compaction of mechanically alloyed aluminium and silicon carbide powders. Materials Science Forum 396-402:289-294 